\title{
Ang Diskurso ni Feorillo Petronilo Demeterio Tungkol sa Pilosopiyang Pilipino: Isang Pagsusuri
}

Ben Carlo N. Atim

\begin{abstract}
This paper has two objectives: first, to highlight the salient points of F.P.A. Demeterio's discourse on Filipino philosophy; and second, to clarify some arguments from his critical discourse. I hope to do this by firstly, accentuating the important points of Demeterio's discussion on Filipino philosophy. The paper, in addition to providing observations of my own, shall consider the following: a) the state and direction of studies on Filipino philosophy; b) an interdisciplinary methodology for Filipino philosophizing; c) the task of philosophers doing Filipino philosophy; and d) analyzing which philosophical traditions, areas, and/or schools of thought should scholars focus on in order to further develop Filipino philosophy. Afterwards, I wish to present what Demeterio calls as Kritikal na Pilosopiyang Filipino (Critical Filipino Philosophy). Lastly, in my conclusion, I endeavor to provide a critical examination of Demeterio's discourse on Filipino philosophy. I shall argue that the challenges he brought to light in his studies are to be considered as important and valuable contributions to the study of Filipino philosophy itself.
\end{abstract}

Keywords: Demeterio, Filipino philosophy, critical theory, critical Filipino philosophy

\section{Panimula} alang nagkakaisang pananaw tungkol sa Pilosopiyang Pilipino sa sumusunod na usapin: a) konsepto at kahulugan, b) kairalan, at c) estado at direksyon. ${ }^{1}$ Sa usaping konseptuwal o kahulugan,

${ }^{1}$ Iba-iba ang pananaw ng ilang Pilipinong pilosoper sa tatlong kategorya na nabanggit. Halimbawa, sa unang kategorya nandiyan sina Napoleon Mabaquiao, Rolando Gripaldo, at Florentino Timbreza na nagbigay ng magkakaibang pananaw sa kahulugan o konsepto ng pilosopiyang Pilipino. Sa pangalawang kategorya, pinangungunahan nina Rolando Gripaldo,

(C) 2017 Ben Carlo N. Atim

https://www.kritike.org/journal/issue 21/atim december2017.pdf

ISSN 1908-7330

$(c c)$ BY-NC-ND 
umiikot ang usapin sa tanong na: Ano ba ang ibig sabihin ng Pilosopiyang Pilipino? Sa usaping kairalan naman ay ang tanong na: Mayroon bang Pilosopiyang Pilipino o wala? Habang sa usaping estado ay: Saan patutungo ang Pilosopiyang Pilipino? Mayabong na ba ito o hindi pa? Sa tatlong nabanggit, nabibilang sa pangatlong kategorya ng usapin ang kabuuang diskurso ni Feorillo Petronilo A. Demeterio habang ang unang dalawang usapin naman ay pahapyaw niyang binigyang pansin. Ngunit sa pag-unawa sa diskurso ni Demeterio, ang unang dalawang usapin ay hindi maiiwasan dahil sa una, mahalaga na maintindihan at malaman kung ano ang kahulugan ng salitang Pilosopiyang Pilipino kapag ito ay ginagamit sa diskurso at pangalawa, ang di-mapaghiwalay na ugnayan ng kahulugan-kairalan at estado o direksyon.

Pangunahing hangarin ng papel na ito ang magbigay ng isang pagunawa o palagay sa diskurso ni F.P.A. Demeterio tungkol sa Pilosopiyang Pilipino sa pamamagitan ng pagbigay-pansin sa mahahalagang puntos ng kanyang diskurso. Layunin din ng papel na ito na ilahad ang kahulugan ng Pilosopiyang Kritikal na kanyang isinusulong.

Nahahati ang papel sa mga sumusunod na bahagi: ang una ay tungkol sa mga mahahalagang palagay o puntos sa diskurso ni Demeterio tungkol sa Pilosopiyang Pilipino. Ang mga puntos na ito ay: una, tungkol sa estado at direksyon ng Pilosopiyang Pilipino; pangalawa, tungkol sa metodolohiya at estraktura sa pag-aaral na kanyang pinapalagay ay mahalaga sa pag-aaral ng Pilosopiyang Pilipino; pangatlo, ang mga dapat gawin ng mga Pilipinong pilosoper sa Pilosopiyang Pilipino; at pang-apat ay ang pagbigay-riin sa paglisan sa iilang tradisyon ng pilosopiya na walang magandang maidudulot sa pilosopiyang Pilipino. Kalakip ng mga nasabing puntos ay mga mahahalagang puna rito. Ilan sa mga puna ay ang sumusunod: a) ang interdisiplinaryong metodo na dapat gamitin ng pilosopiya sa sarili nitong pagsusuri sa mga pilosopikal na suliranin; b) ang ugnayan ng kahulugan at estado sa usaping Pilosopiyang Pilipino; c) ang limitadong sakop ng tungkuling etikal at ideyolohikal ng mga namimilosopiya sa Pilosopiyang Pilipino; at d) ang pagtingin sa ibang pilosopiya bilang walang pakinabang at dapat lisanin na lamang. Samantala, ang pangalawang pangkalahatang layunin ng papel na ito ay ang paglalahad hinggil sa kahulugang gamit ni Demeterio sa tinawag niyang Kritikal na Pilosopiyang Pilipino (KPP). Sa aking palagay mahalaga ang ginagampanang tungkulin ni Demeterio sa pagpapaunlad ng diskurso sa pilosopiyang Pilipino. Bilang tanda ng kanyang mahalagang kontribusyon sa pilosopiyang Pilipino ay ang mga bagong mahahalagang sibol na mga pananaliksik sa

Leonardo Mercado, at Romualdo Abulad ang usapin dito. Sa panghuling kategorya masasabing binigyan ng masusing pagsusuri ang estado ng Pilosopiyang Pilipino ni F.P.A. Demeterio at Rolando Gripaldo. Habang si Emerita Quito naman sa aking pagkakaalam ang nagsimulang sumuri sa paksang ito. 
pilosopiyang Pilipino na ang gamit na batayan, metodolohiya o modelo ay hango sa gawa ni Demeterio. Nariyan ang mga panulat halimbawa nina Emmanuel C. De Leon ${ }^{2}$ at Leslie Anne L. Liwanag ${ }^{3}$ na gumamit ng pananaw at batayan, o modelo ay ang taksonomiya na Demeterio.

\section{Mga Mahahalagang Puntos at Puna sa Diskurso ni Feorillo Petronilo Demeterio tungkol sa Pilosopiyang Pilipino}

Sa puntong ito, nais kong bigyan-pansin ang mga mahahalagang palagay na isinusulong ni F.P.A. Demeterio sa kanyang diskurso tungkol sa pilosopiyang Pilipino. Ngunit, bago ito, bibigyan pansin ko muna ng kaunti ang akademikong buhay ni Demeterio bilang isang mahalagang aspekto para mas maunawaan ang kanyang pananaw hinggil sa Pilosopiyang Pilipino.

Si Feorillo Petronilo A. Demeterio ay nakapagtapos ng kanyang doktorado sa Araling Pilipino sa Unibersidad ng Pilipinas noong 2004, habang ang masteral at undergradweyt diploma sa Unibersidad ng Sto. Tomas. Siya ay nakapagturo sa iba't ibang pamantasan tulad ng San Beda College-Manila, Unibersidad ng Sto. Tomas, at De La Salle UniversityManila. Ang panghuli ang siyang kanyang kasalukuyang pamantasan kung saan siya ay direktor ng pananaliksik ng unibersidad at nagtuturo sa iba't ibang asignatura sa pilosopiya at Araling Pilipino.

Siya din ay nakapaglimbag ng mga akda. Ang ilan sa mga ito ay ang From Exceptionality to Exceptional: Inclusion of Differently-Abled Persons in the Workplace (2014), Ferdinand Blumentritt and the Philippines: Insights and Lessons for Contemporary Philippine Studies (2013), Ang mga Ideolohiyang Politikal ng Catholic Bishop's Conference of the Philippines: Isang Pag-aaral sa mga Piling Pahayag mula sa Limang Panahon ng Kontemporaryong Eklesiastiko-Politikal na Kasaysayan ng Pilipinas (2012). Maliban sa mga nabanggit, mahalaga sa pagaaral na ito ang kanyang mga sanaysay sa Pilosopiyang Pilipino tulad ng mga sumusunod: Quito, Ceniza, Timbreza, Gripaldo: DLSU Professors' Contributions to Filipino Philosophy (2014), Assessing the Development Potentials of some Twelve Discourses of Filipino Philosophy (2014), Status of and Directions for "Filipino Philosophy" in Zialcita, Timbreza, Quito, Abulad, Mabaquiao, Gripaldo, and Co (2013), Ang Kallipolis at ang ating Kasalukuyang Lipunan: Isang Pakikipagdiyalogo ng Kritikal na Pilosopiyang Filipino sa Ang Republika ni Platon (2011), Thomism

\footnotetext{
${ }^{2}$ Emmanuel C. de Leon, “Ang Pilosopiya at Pamimilosopiya ni Roque J. Ferriols, S.J.: Tungo sa Isang Kritikal na Pamimilosopiyang Filipino," in Kritike: An Online Journal of Philosophy 9:2 (2015), 28-50; Emmanuel C. de Leon, “Emerita S. Quito (1929--): Ang Ugat ng Isang Panibagong Direksiyon ng Pamimilosopiya sa Pilipinas," in Malay 29.2 (2017): 30-46.

${ }^{3}$ Leslie Anne L. Liwanag, "Ang Pilosopiya ni Sr. May John Mananzan, OSB," in Kritike: An Online Journal of Philosophy, 9:2 (2015): 51-76; Leslie Anne L. Liwanag, "Ang Pilosopiya ni Emerita S. Quito," Kritike: An Online Journal of Philosophy 10:1 (2016): 54-82.

(c) 2017 Ben Carlo N. Atim

https://www.kritike.org/journal/issue 21/atim december2017.pdf

ISSN 1908-7330

(c) BY-NC-ND
} 
and Filipino Philosophy in the Novels of Jose Rizal (2005), Defining the Appropriate Locus of Radical Peace Studies in Filipino Philosophy (2002), Thought and SocioPolitics: An Account of the Late 20 $0^{\text {th }}$ Century Filipino Philosophy (2002), at ReReading Emerita Quito's Thoughts on the Underdevelopment of Filipino Philosophy (2000). Itong mga sanaysay ay gagamitin ng papel ko bilang pangunahing materyal sa pag unawa ng diskurso ni Demeterio tungkol sa pilosopiyang Pilipino.

Para sa gamit ng papel na ito, hahatiin ko ang mga nabanggit na sanaysay sa dalawang yugtong-diskurso: ang unang yugto ay tatawagin kong problematique stage. Ito ay mga sanaysay na sinulat niya simula noong 2000-2004; at ang pangalawang yugto naman ay tatawagin kong probing stage. Sa yugtong ito nabibilang ang kanyang mga sanaysay na nasulat simula noong 2005-2014. ${ }^{4}$ Kung bakit ko sinabing problematique stage ang unang yugto ay dahil sa ang mga ito ay nagbibigay-riin sa pangunahing suliraning teoretikal ng pilosopiyang Pilipino. Sa unang mga sanaysay makikita ang pangunahing adhikain ni Demeterio tungkol sa pilosopiyang Pilipino. Itong adhikain ay ang paghain ng sagot sa tanong na kung bakit: una, underdeveloped ang pilosopiyang Pilipino ayon kay Emerita Quito, at pangalawa, bakit walang maituturing na tunay na masasabing pilosopiyang Pilipino. Sa kanyang sanaysay, halimbawa, na Re-Reading Emerita Quito's Thoughts on the Underdevelopment of Filipino Philosophy ${ }^{5}$ sinentro ni Demeterio ang usapin sa pananaw ni Quito hinggil sa mga dahilan kung bakit mabagal ang pag-usbong ng pilosopiyang Pilipino sa bansa at lalo't hinggit ang tanong na kung bakit wala pang masasabing isang umiiral na tunay na pilosopiyang Pilipino. Dito nagsimula at nakaugat ang diskurso ni Demeterio. Habang ang mga patunay sa mga dahilan ng mabagal na pag-usbong o pagka-walang tunay na pilosopiyang Pilipino ay makikita sa pangalawang yugto ng kanyang diskurso. Dito, sa probing stage, ipinakita ni Demeterio sa pamamagitan ng paggamit ng bibliograpikal na tala maraming pilosopikal na akda na ang nailimbag. Ayon pa sa kaniyang pag-aaral, mayroong mahigit na labimpitong uri ng pilosopiyang Pilipino ${ }^{6}$ ang lumutang at labing-dalawa sa mga ito ay mga uring pilosopikal na kapaki-pakinabang na linangin para sa pagpapaunlad nang husto ng pilosopiyang Pilipino.

${ }^{4}$ Ang kategoryang ito ay isang arbitraryong gamit lamang upang maipakita nang malinaw ang daloy at sistematikong programa ng diskurso ni Demeterio.

${ }^{5}$ F.P.A. Demeterio III., "Re-Reading Emerita Quito's Thoughts Concerning the Underdevelopment of Filipino Philosophy," in Academia, < $\underline{\text { https://www.academia.edu/7340197 }}$ Re-Reading Emerita Quitos Thoughts Concerning the Underdevelopment of Filipino Philosophy>. Hereafter cited as "Re-Reading Emerita Quito."

${ }^{6}$ F.P.A. Demeterio III, "Status of and Directions for 'Filipino Philosophy' in Zialcita,

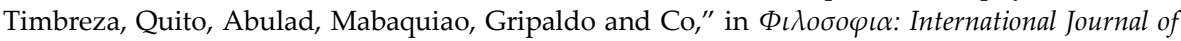
Philosophy 14:2 (2013), 185-214. Hereafter cited as "Status of and Directions for 'Filipino Philosophy.'"

(C) 2017 Ben Carlo N. Atim

https://www.kritike.org/journal/issue 21/atim december2017.pdf

ISSN 1908-7330 


\section{2}

DEMETERIO AT PILOSOPIYANG PILIPINO

Samantala, ang unang pangkalahatang layunin ng papel na ito ang magbigay ng mahahalagang puntos sa diskurso ni Demeterio. May dalawang bahagi ang layuning ito: una, ang ipaliwanag ang mga mahahalagang puntos na ito; at pangalawa, ang magbigay ng puna tungkol sa nasabing puntos.

\section{Ang Estado at Direksyon ng Pilosopiyang Pilipino}

Mayabong na marahil ang pilosopiyang Pilipino ayon sa pag-aaral ni Demeterio. Sa usaping ito, dalawang sanaysay ang dapat tignan: ang Assessing the Development Potentials of Some Twelve Discourses of Filipino Philosophy at ang Status of and Directions for "Filipino Philosophy" in Zialcita, Timbreza, Quito, Abulad, Mabaquiao, Gripaldo, and Co. Nabibilang ang mga sanaysay na ito sa pangalawang yugto (probing stage) ng diskurso ni Demeterio. Pangunahing usapin dito ay ang pagbibigay ng isang komprehensibong datos at pagsasalarawan sa estado at direksyon ng pamimilosopiyang Pilipino. Ngunit, para mas maunawaan ang pinanggagalingan ng pananaw ni Demeterio tungkol rito, mahalagang suriin ang unang yugto ng kanyang diskurso dahil dito nagmumula ang dahilan sa pagsasalarawan ng estado at direksyon ng pilosopiyang Pilipino.

Tingnan natin ang unang yugto ng diskurso ni Demeterio na siyang pinanggagalingan ng kanyang diskurso sa direksyon at estado ng pilosopiyang Pilipino. Dito sa unang yugto makikita ang teoretikal na suliraning bumabalot sa usapin ng pilosopiyang Pilipino tulad ng: a) underdevelopment ng pilosopiyang Pilipino ayon kay Quito, at b) ang kawalan ng tunay na tinatawag na pilosopiyang Pilipino. Nakapaloob sa dalawang suliranin na ito ang pagtatangka ni Demeterio na maghain ng sagot at patunay.

Ang unang suliranin ay tungkol sa underdevelopment ng pilosopiyang Pilipino. Maiuugnay ito, ayon sa kanya, sa apat na mahahalagang problema na kailangang bigyan ng konkretong solusyon. Ito ay ang historikal, ekonomikal/institusyunal, kultural, at linggwistikong suliranin ng pilosopiyang Pilipino. ${ }^{7}$ Habang ang pangalawang suliranin naman ay patungkol sa kawalan ng tunay na pilosopiyang Pilipino na maiuugnay din sa unang nasabing mabigat na problema ng pilosopiyang Pilipino. Bigyan natin ng maiksing paliwanag ang dalawang mahahalagang suliranin na ito.

Ayon kay Demeterio, sinasabi ni Quito na ang historikal na suliranin kung bakit wala o mabagal ang pag-usbong ng pilosopiyang Pilipino noong kapanahunan niya ay dahil sa uri ng pamimilosopiya sa bansa na nakasentro sa pilosopiyang Tomistiko. Sang-ayon si Demeterio rito, ngunit may mas malalim pang dahilan ang suliraning ito ayon sa kanya. Ito ay ang baluktot

${ }^{7}$ Demeterio, “Re-Reading Emerita Quito," 6-8.

(c) 2017 Ben Carlo N. Atim

https://www.kritike.org/journal/issue 21/atim december2017.pdf

ISSN 1908-7330

(c) BY-NC-ND 
na pananaw o konsepto ng pilosopiya na maaaring maiugnay ang bakas nito sa Tomistikong pilosopiya ng bansa. ${ }^{8}$ Pinapalagay ni Demeterio na ang Tomistikong pamimilosopiya ay binabalewala ang ilang elementong nakapaloob sa ideyal na estruktura ng pilosopikal na pagsusuri. Ito ay ang pagtatanong (question), paghahanap (search) ng sagot sa tanong, sagot sa tanong (answer), at paglalagay ng sagot sa teorya o tradisyon kung saan ito puwedeng maiuuri. ${ }^{9}$ Subalit hindi ito nasusunod. Madalas, ayon kay Demeterio, humihinto ang lahat sa isang elemento lamang - sa sagot.

Sa pagsusuri ni Demeterio sinasabi ni Quito na ang ekonomikal/institusyunal na suliranin ay tumutukoy sa mahinang suporta ng mga akademikong institusyon sa gawaing akademiko tulad ng pananaliksik sa bansa. Ngunit sa paglipas ng panahon, unti-unti itong napunan. Ang problema na lamang ayon kay Demeterio ay kung papaano aktibong magtutulungan at magpapalitan ng mga diskurso at palagay ang mga pilosoper para magkaroon ng tunay na pilosopiyang Pilipino. Dagdag pa niya, ang kailangan sa ngayon ay katalista na siyang pagmumulan ng lakas sa pagsisimula o pagbubuo ng diskursibong gawain. ${ }^{10}$ Walang ibang nakita si Demeterio bilang puwedeng maging katalista kundi ang mga Pilipinong namimilosopiya at nagtuturo ng pilosopiya sa bansa.

Ang kultural na suliranin naman ayon kay Quito na binanggit ni Demeterio ay dahil sa Pilosopo Tasyo syndrome. Ang pagtingin sa pilosopiya bilang isang pangangatuwirang nakaka-pikon ng kausap at labas-samundong usapin. Subalit, ayon kay Demeterio, hindi dahilan si "Pilosopo Tasyo" kung bakit walang umuusbong na tunay na pilosopiyang Pilipino, kung hindi dahil sa oral culture na siyang sagabal sa pagpapaunlad nitong pilosopiya. Sinasabi ni Demeterio na ang natira (residual) ng oral culture sa kamalayan ng mga Pilipino ay siyang humahadlang para hindi makausad o yumabong ang pilosopiya sa bansa. Ito ay maituturing na isang hamon para sa mga namimilosopiya na baguhin ang kamalayan tungo sa literate culture na sinasabing hindi pa tuluyang nangyayari sa ngayon. Ang panghuling dahilan ay ang kakulangan ng linggwaheng pilosopikal (philosophical language) ng pilosopiyang Pilipino. Sinabi ni Demeterio na ayon kay Quito, ito ay dahil kulang ang mga nag-aaral sa pilosopiya na marunong magbasa ng mga pilosopikal na akda ng mga tanyag na pilosopo sa pangunahing wika nito tulad halimbawa nina Immanuel Kant at Martin Heidegger (Aleman), Rene Descartes at Alain Badiou (Pranses), Plato at Aristoteles (Griyego), o Santo Tomas at San Agustin (Latin). Ngunit, hindi sang-ayon dito si Demeterio. Sinasabi niya na hindi ito ang talagang suliranin ng pilosopiyang Pilipino kundi ang kasalatan sa linggwaheng pilosopikal na siyang

${ }^{8}$ Ibid., 10.

${ }^{9}$ Ibid., 9.

${ }^{10} \mathrm{Ibid} ., 11$.

(C) 2017 Ben Carlo N. Atim https://www.kritike.org/journal/issue 21/atim december2017.pdf ISSN 1908-7330 


\section{DEMETERIO AT PILOSOPIYANG PILIPINO}

pangunahing pangangailangan para sa isang pilosopikal na diskurso. Para matugunan ang pangangailangan ng pilosopiyang Pilipino na maipaangat ang pagkakakilanlan nito, kailangan ng sapat na mga teorya, metodo, paradaym at konseptong pilosopikal. Nagbigay ng ilang sanhi si Demeterio kung bakit salat sa lenggwaheng pilosopikal ang pilosopiyang Pilipino. Una, ito ay dulot ng walang matatag na tekstwal na tradisyon kung saan pwedeng humugot ng mga kailangang teorya o metodo sa pamimilosopiya. Ang malinaw na dahilan ay ang pananatili ng culture of orality sa kamalayan ng mga Pilipino; pangalawa, ang baluktot na pag-unawa sa pilosopiya dulot ng pagsakop sa pilosopikal na kamalayan ng Tomistikong pamimilosopiya sa bansa; pangatlo ay ang pag-alinlangang gumamit ng mga kanluraning teorya at metodo sa pilosopiya, sosyolohiya, at pag-aaral kultural (cultural studies) bilang mga epektibong instrumentong makatutulong sa pag-unawa at pagdalumat sa karanasan at pangkalahatang pananaw ng mga Pilipino. ${ }^{11}$

Sa pangalawang yugto ng diskurso ni Demeterio kung saan ang kanyang puna ay nakatuon sa estado at direksyon ng pilosopiyang Pilipino, dalawang mahahalagang bagay ang dapat tandaan: una, ang pagpapakita ng positibong pagtingin sa pilosopiyang Pilipino sa pamamagitan ng pagsipat sa mga naging posisyon ng mga respetadong pilosoper tulad nina Quito, Abulad, Gripaldo, Timbreza, Zialcita, Co, at Mabaquiao. ${ }^{12}$ Dito pinakita ni Demeterio na may mga ilang uri ng pilosopiyang Pilipino ang naitatag na at ang mga ito ay may malakas na potensyal ng pag-unlad katulad ng mga sumusunod: critical philosophy (both academic and non-academic), interpretation of Filipino worldview, phenomenology/existentialism, logical analysis, appropriation of foreign theories, appropriation of folk philosophy, breakthrough writing, discourse on local themes, at discourse on universal and foreign themes. ${ }^{13}$ Pangalawa na dapat tandaan: ang di-direktang pahiwatig ng pagyabong ng pilosopiyang Pilipino ayon na rin sa mga natuklasang samu't-saring uri ng pamimilosopiya sa bansa. Ayon kay Demeterio, mahalaga na pagtuunan ng pansin ang mga ilang uri ng pilosopiyang may malakas na potensyal na lumago at umunlad, pansinin ang kahinaan at kalakasan nito at magbigay na karampatang pagsusuri para mas lalong pang mapaunlad ang mga ito. Samakatuwid, masasabi natin na para kay Demeterio may malinaw na estado at direksyon ng pilosopiyang Pilipino batay na rin sa kanyang pagsusuri at pagkakategoriya o pag-uuri ng mga akda ng mga Pilipinong pilosoper. Dito sa yugtong ito, lumabas na mayroon nang matibay na mga tradisyon ng pilosopiya sa bansa kahit noong panahon pa ni Emerita Quito.

\footnotetext{
${ }^{11}$ Ibid., 12.

${ }^{12}$ Ngunit kapuna-puna rin dito ang hindi pagkabilang sa listahan nina Roque Ferriols at Leonardo Mercado.

${ }^{13}$ Demeterio, "Status of and Directions for 'Filipino Philosophy,'” 212.

(c) 2017 Ben Carlo N. Atim

https://www.kritike.org/journal/issue 21/atim december2017.pdf

ISSN 1908-7330
}

(c) BY-NC-ND 
Sinasabi ng papel na ito na may dalawang yugto ang diskurso ni Demeterio. Ang una ay ang yugtong tumatalakay sa konseptwal o teoretikal na usapin sa suliranin ng estado ng pilosopiyang Pilipino. Nabanggit din ng papel na ito na ang diskurso ni Demeterio ay nakatuon sa usaping estado at hindi sa kahulugan at kairalan ng pilosopiyang Pilipino. Ang pangalawang yugto ay tumatalakay sa konkretong sagot at programa para sa pagpapayabong ng pilosopiyang Pilipino. Nakatuon ang usapin sa yugtong ito sa mga lumutang na iba't ibang uri ng tradisyong pilosopikal sa bansa.

Ngunit may mga ilang puna na gustong ipahayag ang papel na ito. Maliban sa mga mahahalagang puntos na nailahad sa itaas, mahalaga din na suriin ang ilang mga di-kapansin-pansin na kahinaan ng unang puntong nabanggit. Ilan sa mga kahinaan ng punto na ito ay ang sumusunod:

Una, ang komento niya hinggil sa tanong kung mayroon nga bang pilosopiyang Pilipino o wala bilang isang 'walang silbi' at insulto sa mga tagapanday ng pilosopiyang Pilipino. May koneksyon ang komentong ito sa kabuuan ng kanyang diskurso sa pangawalang yugto dahil kung atin itong papansinin, ang dahilan kung bakit pinapakita ni Demeterio sa kanyang diskurso ang materyal na datos ay para patunayan na mayroong pilosopiyang Pilipino at masasabi din na sa simula't simula pa lamang ay naniniwala na siya na mayroong masasabing pilosopiyang Pilipino.

Sa pananaw ni Demeterio isang pagsasayang ng lakas at oras ang pag-isipan, pagsuri, at paghanap ng sagot sa ganoong uri ng tanong. Sa kanyang akda na Status of and Directions for "Filipino Philosophy in Zialcita, Timbreza, Quito, Abulad, Mabaquiao, Gripaldo, and Co, naging laman ng kanyang panimula ang tanong na Meron bang Pilosopiyang Pilipino? Hindi man tahasan at kategorikal ang kanyang tugon dito, kapansin-pansin naman ang positibo nitong pagtingin sa kairalan ng pilosopiyang Pilipino. Ang kanyang positibong posisyon ang nagtulak sa kanya para pasaringan ang iilang may duda o hindi naniniwala na mayroong umiiral na pilosopiyang Pilipino. Ayon sa kanya, ang tanong ay walang silbi at isang pang-iinsulto sa kamalayan at kakayanang intelektuwal ng mga Pilipinong namimilosopiya. Sang-ayon ako kay Demeterio sa kanyang palagay hinggil dito, na ang tanong sa unang pagtingin ay nakaiinsulto. Subalit ito lamang ay kung ang gamit natin ng salitang pilosopiya ay di-istrikto. ${ }^{14}$ Kontra Demeterio, sa aking palagay ang tanong na kung mayroon bang pilosopiyang Pilipino o wala ay hindi isang pang-iinsulto kung uunawain natin ang kahulugan ng pilosopiyang Pilipino sa istrikto nitong gamit. Ang tanong ay lehitimo at may

\footnotetext{
${ }^{14}$ Napoleon Mabaquiao, "Isang Paglilinaw sa Kahulugan at Kairalan ng Pilosopiyang Filipino," in Malay 24:2 (2012), 39-56. Sang-ayon din ako sa pananaw ni Mabaquiao na ang gamit sa pilosopiyang Pilipino ay dapat istrikto. Malinaw ang pahayag ni Mabaquiao rito. Hindi maaaring lahat ng kaisipan ay maituturing na pilosopiyang Pilipino dahil kung magkagayon, wala nang dapat pang disiplinang matatawag na pilosopiyang Pilipino.
} 
kawastuhan. Ang layunin ng tanong ay maghanap ng malinaw na pagunawa sa mga konseptong napapaloob rito. Isa din itong hamon na kailangan pagtagumpayan. Mas mauunawaan ang kahalagahan ng nasabing tanong kung atin ito ilalagay sa kanyang tamang konteksto at layunin. Sa puntong ito, dapat malinaw kung ano ba ang pinapalagay ng nagtatanong kung bakit niya tinatanong kung mayroon bang pilosopiyang Pilipino o wala? Mahalaga din na itanong natin kung ang tanong ba na Meron bang Pilosopiyang Pilipino? ay pilosopikal o hindi. Ito ay nakadepende sa kung ano ang ibig natin sabihin ng pilosopikal at di-pilosopikal na tanong. Ang tanong ay pilosopikal kung ito ay foundational at nangangailangan ng masusing pag-unawa at pagsuri sa paksa na napapaloob sa tanong gamit ang katuwiran at argumento. Ang pilosopikal na tanong ay hindi nangangailangan ng eksaktong sagot, ang mahalaga ay ang pagbubuo ng argumento sa pagsagot ng tanong. Balikan natin ang tanong na Is there a Filipino philosophy? Ito ba ay pilosopikal o hindi? Nakaiinsulto o hindi? May halaga o wala? Masasabing pilosopikal ang tanong, hindi nakaiinsulto, at may halaga. Pilosopikal dahil dinadala tayo nito sa pinakaugat-ang kairalan ng isang bagay na nangangailangan ng pananaw at palagay o argumento bilang pagpapatunay. Hindi nakaiinsulto dahil ang pilosopikal na tanong ay hindi dapat nakapokus sa emosyonal na aspekto bagkus ay dapat kognitibo. Mahalaga sapagkat ito ay humahamon sa kakayahan ng pilosopiya na magbigay linaw sa mga konseptong binubuo at isinusulong nito.

Ano ngayon ang implikasyon nito sa unang mahalagang punto ni Demeterio? Bagaman mahalaga ang naiambag ng pananaliksik ni Demeterio sa estado at direksyon ng pilosopiyang Pilipino, mayroon din naman itong kakulangan pagdating sa pagbibigay ng matibay na pundasyon sa pagunawa ng malinaw sa tinutukoy nitong estado at direksyon ng pilosopiyang Pilipino. Sa maikling sabi, binigyan-pansin sana ni Demeterio ang usapin sa katuturan, kahulugan, at kairalan ng pilosopiyang Pilipino para mas lalong mapatibay nito ang diskursibong kakayanan ng kanyang mga puntos.

May dalawang mahahalagang konsiderasyon kung bakit dapat binigyan-pansin nito ang suliranin sa kahulugan at kairalan ng pilosopiyang Pilipino. Una, malinaw na konteksto at kahulugan sa paggamit sa salitang pilosopiyang Pilipino, at pangalawa, malinaw na batayan sa pag-uuri ng mga akda na maituturing na pilosopikal. Sa diskurso ni Demeterio ang mga dahilang ito ay walang malinaw na pagpapahayag o kung hindi man ay wala siyang hayagang pahayag tungkol sa uri ng kontekstong ginagamit sa salitang "pilosopiyang Pilipino" at ganoon din sa batayan sa pag-uuri ng mga akda.

Pangalawa, sa unang tingin may kontradiksyon na namamagitan sa kanyang dalawang magkaibang puna na makikita sa dalawang yugto ng kanyang diskurso. Sa unang yugto, sinasabi ni Demeterio na walang sapat o

(c) 2017 Ben Carlo N. Atim

https://www.kritike.org/journal/issue 21/atim december2017.pdf

ISSN 1908-7330

(cc) BY-NC-ND 
salat sa pilosopikal na wika ang pilosopiyang Pilipino kaya kakaunti lamang ang mga teorya, metodo, o konsepto na maaaring gamitin sa pag-aaral rito. Ang implikasyon ay walang matatag na tradisyon kaya walang nangyayaring pag-usbong ng tunay na pilosopiya sa bansa. Samantalang sa pangalawang yugto, pinakita niya na may labinpitong uri ng pilosopiyang Pilipino at ilan dito ay may malakas na potensyal na paunlarin at pagyabungin. Ibig sabihin, pinatunayan din ni Demeterio na ang una niyang suri sa suliranin ng pilosopiyang Pilipino ay wala ng bisa o di kaya ay hindi totoo na may suliranin sa pilosopikal na lengguwahe ang pilosopiyang Pilipino. Ngunit sa kabuuan, masasabing pa din na ang puna ni Demeterio tungkol sa suliraning konseptuwal o teoretikal at sa estado at direksyon ng pilosopiyang Pilipino ay mahalaga sa pagpapanday ng mas matibay na saligan sa pamimilosopiyang Pilipino. Bagaman may kakulangan sa iilang aspekto, ito naman ay madaling matugunan sa pamamagitan ng mas masusing pagsusuri pa rito na pwedeng gawin ninuman na interesado sa ganitong usapin.

Kaugnay ng unang punto sa diskurso ni Demeterio, ang susunod na bibigyan pansin ng papel na ito ay tungkol sa uri ng metodohikal na estrakturang ginamit ni Demeterio sa kanyang diskurso at ang isyu sa ugnayan ng pilosopiya at sa ibang disiplina katulad ng Araling Panlipunan (social science).

\section{Metodolohiya, Pilosopiya, at Araling Panlipunan: Tungo sa Mayabong na Pananaliksik sa Pilosopiyang Pilipino?}

Isang interdisiplinaryo na maituturing ang metodolohiya na ginamit ni Demeterio sa kanyang diskurso tungkol sa pilosopiyang Pilipino. Para maunawaan kung bakit ko ito nasabi, tingnan muna natin ang kanyang intelektwal na pinanggagalingan at akademikong kapaligiran.

Tulad ng aking nabanggit sa itaas, mapapansin na siya ay hindi lamang hinubog ng pilosopiya kung hindi pati na rin ng iilang sangay ng disiplina sa araling panlipunan at araling Pilipino. Sa kanyang sanaysay na Speculations on the Dis/Junction Point between Philosophy and the Social Sciences sinabi niya na ang kanyang pagkamulat sa interdisiplinaryong pag-aaral ay nagsimula pa noong siya ay nasa kolehiyo pa lamang hanggang sa napunta siya sa Unibersidad ng Pilipinas (Diliman) para kumuha ng doktorado sa Araling Pilipino (Philippines Studies). ${ }^{15}$ Mahalagang isaalang-alang ito dahil

\footnotetext{
${ }^{15}$ F.P.A. Demeterio III, "Speculations on the Dis/Junction Point between Philosophy and the Social Sciences," in Academia <https://www.academia.edu/7340224/ Speculations on the Dis Junction Point between Philosophy and the Social Sciences>. Hereafter cited as "Speculations."
} 
mayroong itong kaugnayan sa uri ng kanyang pamamaraang pananaliksik at metodolohiya sa pagsusuri sa mga suliranin ng pilosopiyang Pilipino.

Masasabing interdisiplinaryo ang metodolohiya ni Demeterio dahil una, ang kanyang pilosopikal na pananaliksik ay ginagamitan ng ibang metodo at teoryang likas na hindi pilosopikal, at pangalawa, nakabatay ito sa kritikal na tradisyon na kanyang sinusulong. Sa Speculations sinasabi ni Demeterio na ang pilosopiya at araling panlipunan ay may parehong hangarin at maaaring magsanib puwersa para mas lalong mapatibay ang mga pananaliksik ng pilosopiyang Pilipino. Ang pilosopiya, ayon sa kanya, ay maaring humiram ng mga epektibong pamamaraan o metodolohiya sa ibang disiplina para sa sarili nitong mga gawaing akademiko, gayon din naman ang araling panlipunan sa pilosopiya. Ibig sabihin, makakakuha ng aral ang bawat disiplina sa ganitong sistema at mas mapapaigting pa nito ang kanilang kanya-kanyang mga adhikain kung nagbibigayan sila ng mga pahayag at pagtingin sa iba't ibang paksa maging teoretikal o praktikal man ito. Sang-ayon ako kay Demeterio sa pananaw na dapat interdisiplinaryo ang pilosopikal na pananaliksik dahil hindi naman talaga ito maiiwasan sa pagsusuring pilosopikal. Ang mga pilosopikal na pananaw halimbawa nina Descartes, Heidegger, Husserl, Marion, Chalmers, at Searle ay binubuo ng mga pahayag at suporta na hindi lang nanggagaling sa pitak ng pilosopiya kundi sa ibang disiplina tulad ng natural science at iba pa. Ibig sabihin, silang mga pilosopo ay tumatawid sa ibang teritoryo para mangalap ng mahahalagang pananaw para gamitin bilang suporta o panlaban sa sinusulong nilang argumento. Sina John Searle at David Chalmers, halimbawa, ay mga kilalang pilosopo sa larangan ng Philosophy of Mind. Upang maisulong ang kanilang pilosopikal na pananaw, kailangan nila masuri ang mga natuklasang datos sa likas na agham (natural science) o neuroscience para malinaw nilang maipahayag ang kanilang isinusulong na argumento tungkol sa malay (consciousness) at isip. Samakatuwid, likas sa pilosopikal na diskurso ang pagiging interdisiplinaryo nito.

Pinapalagay rin ni Demeterio na puwedeng humiram ng metodolohiya o teorya ang pilosopiya upang mapatibay nito ang sariling mga posisyon, pananaw at adhikain. Hindi kailangan ng pilosopiya na ikulong ang sarili nito sa abot-tanaw ng kanyang teritoryo at sa pagiging pagka-ekslusibo. Bagkus, kailangan nitong lisanin ang nakagisnang paniniwala na nasa sarili lang nito makakakuha ng sapat na konsepto at teorya upang maglinang ng mga bagong pananaw o pahayag. Ginamit ni Demeterio ang pananaw ni Jürgen Habermas para magbigay ng kritikal na pagtingin sa kalagayan ng pilosopiya at sa pagiging malaya nito sa ibang disiplina. Ayon kay Demeterio, upang mapanatili ng pilosopiya ang kahalagahan nito, kailangang payagan nito ang sariling makipag-alyansa sa

(c) 2017 Ben Carlo N. Atim

https://www.kritike.org/journal/issue 21/atim december2017.pdf

ISSN 1908-7330

(c) $)$ BY-NC-ND 
ibang disiplina tulad ng araling panlipunan. ${ }^{16}$ Kung tama si Demeterio sa kanyang pananaw, mahihirapang panatilihin ng pilosopiya ang sarili nitong pagkakilanlan kung hahaluan nito ang sarili ng mga instrumentong magdudulot ng unti-unting paglaho ng pagkapuro ng diskurso nito. Sa puntong ito, kontra Demeterio, naniniwala akong kayang panatilihin ng pilosopiya ang sarili nitong mundo at umiral na may kabuluhan at kahalagahan bilang isang malayang disiplina na hindi nangangailang ng kaisahan sa ibang disiplinang pang-agham. Katulad ng sinasabi ni Habermas, ayon kay Demeterio, ang pilosopiya ay siyang tagalikha ng mga palagay na pinaghahanguan ng katuwiran at hypotesis na siyang ginagamit ng ibang disiplina sa kanila sariling mga adhikaing pragmatiko. ${ }^{17}$ At malinaw rin kay Habermas na dapat mapanatili ang pagkakaiba ng pilosopiya sa ibang disiplina kahit pa may nangyayaring pagpapalitan (cross-fertilization) ng mga pananaw at pahayag. Malaki ang kaibahan ng pilosopikal na diskurso o pananaliksik sa uri ng pananaliksik ng ibang disiplina. Ang kaibahan ay batay sa sumusunod: (a) uri o kalikasan ng paksa, at (b) metodo. Ang unang uri ay tumutukoy sa paksang pilosopikal. Ang pilosopikal na pananaliksik ay nakainog sa usapin tulad ng metapisika, epistemolohiya, etika, lohika, at iba pang uri na nabibilang sa sangay ng pilosopiya. Ito ay pilosopikal kung ito ay kabilang o may kinalaman sa mga sangay ng pilosopiya. Speculative at argumentibo ang kalikasan ng suliraning pilosopikal at may kinalaman sa kalikasan ng mga bagay-bagay. Hindi nito sakop ang usapin ng agham panlipunan, likas na agham, relihiyon, sosyolohiya, sikolohiya, kasaysayan, at antropolohiya ngunit para magsimulang umusad ng usapin sa mga disiplinang ito, kailangan ng mga ito ang pundasyon na siyang ginagawa ng pilosopiya. ${ }^{18}$ Halimbawa, hindi pilosopikal na usapin kung papaano umiikot ang mundo, kung bakit mayroong langit, kung tayo ba ay produkto ng lipunan o hindi, kung bakit maraming kabataan ang nahuhumaling sa kulturang Koreano, kung kailan o paano at bakit pinatay ang bayaning si Jose Rizal. Maituturing na usaping pilosopikal ang paksa kung ito nagtatanong ng mayroon bang Diyos o wala, may kahulugan ba ang buhay o wala, kung tayo ba ay parehong katawan at isip o isip lamang o katawan laman, at kung mayroon ba tayong matatawag na personal na pagkakakilanlan (personal identity). Ibig kung sabihin, ang likas na agham (natural science), relihiyon,

${ }^{16}$ Ibid., 10 .

${ }^{17}$ Ito din ang pananaw nina Deleuze at Guattari na ang pilosopiya bilang isang malayang disiplina ay responsable sa paglikha ng mga konseptong magagamit hindi lang sa sarili nitong diskurso kundi pati ng ibang disiplina. Gilles Deleuze and Felix Guattari, What is Philosophy?, trans. by Hugh Tomlinson and Graham Burchell (New York: Columbia University Press, 1991), 7.

${ }^{18}$ Malinaw sa pilosopiya ni Rene Descartes na ang lahat ay nagmula sa iisang ugat at ito ay pilosopiya. See Rene Descartes, Meditations on First Philosophy, trans. by John Cottingham (Cambridge: Cambridge University Press, 1996).

(C) 2017 Ben Carlo N. Atim

https://www.kritike.org/journal/issue 21/atim december2017.pdf

ISSN 1908-7330 
sosyolohiya, at iba pa ay may kanya-kanyang mga suliranin na nagsisilbing bakod o tanda ng kanilang disiplina.

Ang pangalawang uri ng kaibahan ng pilosopiya ay metodo na nababatay sa argumento. Kung ang ibang disiplina ay may tinatawag na qualitative o quantitative na uri ng pananaliksik na gumagamit ng instrumentong tulad ng serbey, interbyu, focus-group, at pagdodokyumentaryo ng mga anekdota, ang pilosopiya ay hindi kailangan gumamit ng alinman sa mga nabanggit sapagkat ang pilosopikal na pananaliksik ay sinasagot ang pilosopikal na mga tanong gamit lamang ang katuwiran sa pamamagitan ng pagbibigay o pagbubuo ng argumento na isinusulong ng may akda nito. Tingnan natin ang mga sinulat nila Platon, Aristoteles, Russell, Wittgenstein, Kant, Friedrich Nietzsche, at iba pa. Nakasandal lamang ang kanilang pilosopikal na mga pananaw sa argumento na kanilang isinusulong. Habang ang ibang disiplina naman ay nananaliksik sa pamamamagitan ng pagsisiyasat sa mga pangyayari gamit ang mga empirikal na instrumento na siyang saligan ng kanilang paliwanag ng kanilang paksa. Ang ganitong pagtingin sa pilosopikal na pananaliksik ay may mahalagang tungkuling ginagampanan sa buhay ng pamimilosopiya at ito ay ang paggamit sa katuwiran bilang gabay sa pagtuklas ng mga ideya $o$ kaalaman. Hindi ko sinasabi na ang ibang pananaliksik ay hindi nakabatay sa katuwiran. Ang punto lamang ay ito: hindi tulad ng ibang disiplina tulad ng natural science na ang hypotesis ay batay sa pisikal na pangyayari at bagay sa mundo, ang pilosopikal na tesis o suliranin ay nakabatay lamang sa katuwiran na nahahasa gamit ang lohika.

Sa kabuuan, sinasabing interdisiplinaryo na maisalalarawan ang metodolohiyang ginamit ni Demeterio. Ngunit kung ang tinutukoy niyang interdisiplinaryo ay paggamit ng ibang metodo o teorya ng ibang disiplina, nilulusaw nito ang saklaw ng pilosopiya at nang araling panlipunan. Gaya ng pananaw ni Habermas na ginamit ni Demeterio, hindi kailangan ng isang pagsasanib ng pilosopiya sa ibang disiplina upang maging makabuluhan at kapaki-pakinabang ito sa panahon ngayon. Ang pilosopiya sa sarili nito ay makabuluhan na. Masasabi din na hindi maiuuri ang pilosopikal na metodo sa pananaliksik na qualitative o quantitative dahil hindi nangangailangan ang pilosopikal na pananaliksik ng ganitong instrumentong empirikal maliban sa pangangatuwiran na inihahayag sa pamamagitan ng argumento at lohika.

Sa konteksto ng diskurso ni Demeterio binigyan pansin ang kahalagahan ng alyansa ng pilosopiya at agham-panlipunan. Sa kanyang pananaw walang tunay at konkretong saklaw ang bawat disiplina dahil ito ay diskursibo lamang. ${ }^{19}$ Ang dahilan kung bakit mayroong inilalagay na tanda o saklaw ang iba't ibang disiplina ay dahil, ayon kay Demeterio,

${ }^{19}$ Demeterio, “Speculations,” 9.

(c) 2017 Ben Carlo N. Atim

https://www.kritike.org/journal/issue 21/atim december2017.pdf

ISSN 1908-7330

(c) BY-NC-ND 
hangad ng bawat isa ang magkaroon ng sariling pagkakakilanlan. Kaugnay nito, iminumungkahi ni Demeterio na mas maging epektibo ang paglinang ng pilosopiyang Pilipino kung gagamit tayo ng metodolohiyang hindi man saklaw ng pilosopiya ay epektibong makatutulong sa pagtuklas o pagsusuri ng suliraning pilosopikal. Dito, mahalaga ang palagay ni Demeterio sa pragmatikong antas. Ngunit ang proposisyon ba na ito ay tunay na makatutulong sa pag-angat ng pilosopiyang Pilipino? Kung ang basihan ni Demeterio ay ang pangangailangang kritikal sa pagkilatis sa kondisyong politikal, sosyolohikal, o ekonomikal, malinaw na hindi na kailangan ng pilosopiya ang mga instrumentong panuri ng ibang disiplina para magampanan ang tungkuling pilosopikal nito. Magandang halimbawa ay sina Karl Marx at Hannah Arendt na nagbigay ng mga palagay sa panlipunan o politikal na suliranin sa pamamagitan lamang ng paggamit ng katuwiran at argumento. Hindi naman gumamit si Karl Marx ng empirikal na instrumento para sabihin at patunayan na mayroong hindi pagkakapantaypantay sa lipunan dahil sa kapitalismo na inaabuso ang kakayanan at lakas ng bawat manggagawa. ${ }^{20}$ Hindi kailangan ni John Searle ang empirikal na instrumento sa pananaliksik para sabihin na hindi maituturing ang isang kompyuter o robot na may malay o intentionality dahil wala silang kakayanang maghangad o malaman na sila ay naghahangad o nakararamdam ng pagkagutom o uhaw. Kung tama ang pananaw na ito, ano ang implikasyon nito sa pananaw ni Demeterio? Isa sa maaaring hindi magandang dulot ay ang paglabo ng saklaw o pagkakaiba sa pagitan ng pilosopiya at ng ibang disiplina. Mahalaga na dapat maging malinaw ang ating pananaw sa usapin ng pilosopiyang Pilipino. Kung, halimbawa, sa pag aaral ng pilosopiyang Pilipino ay gagamit tayo ng mga metodolohiyang hindi pilosopikal para isulong ang argumento nais nating patunayan, masasabi pa rin ba na pilosopikal ang ginagawang pananaliksik? At papaano natin masasabi na ito ay pilosopiyang Pilipino? Dito, babalik tayo sa suliraning konseptuwal tulad ng pagbibigay ng tamang kahulugan ng gamit ng salitang pilosopiya at pilosopiyang Pilipino.

Walang problema sa pagiging interdisiplinaryo ng pilosopiya ngunit kung ang pagiging interdisiplinaryo nito ay nangangailangan din ng interdisiplinaryong metodolohiya upang saliksikin ang mga pilosopikal na problema at magsulong ng argumento gamit ang mga instrumentong pangagham, nilalabo nito ang pag-unawa sa pilosopiya lalo't higit sa saklaw na sakop nito. Dagdag pa rito ay ang paglabo ng batayan sa pag-uuri ng mga Pilipinong akda na pilosopikal at di-pilosopikal. Kung gayon, bilang mga namimilosopiyang Pilipino mayroong tungkuling dapat gampanan ang mga

${ }^{20}$ Raymond Geus, The Idea of Critical Theory: Habermas and the Frankfurt School (London: Cambridge, 1981), 1.

(c) 2017 Ben Carlo N. Atim https://www.kritike.org/journal/issue 21/atim december2017.pdf ISSN 1908-7330 
namimilosopiya sa pilosopiyang Pilipino at iba pa para maayos na maipanday ang ating sariling tatak ng pilosopiya. Mismo si Demeterio sa kanyang diskurso ay hindi nagkulang sa pagpapa-alala sa atin nito. Sinasabi niya na mayroon tayong tungkuling etikal na gampanin bilang mga namimilosopiya sa pilosopiyang Pilipino.

\section{Ang mga Dapat Gawin ng mga Namimilosopiya sa Pilosopiyang Pilipino}

Ayon kay Demeterio, may dalawang mabigat at mahirap pero magkaugnay na tungkulin ang mga namimilosopiya sa pilosopiyang Pilipino: a) etikal, at b) ideyolohikal. Ang etikal na tungkulin ay tumutukoy sa pangangailangan ng paggamit ng interdisiplinaryong metodolohiya sa pagsusuring kritikal ng pilosopiyang Pilipino sa mga pangyayaring politikal, sosyolohikal, ekonomikal, kultural, at maging sa relihiyon. Ang ideyolohikal na tungkulin naman ay tumutukoy sa tungkuling maipakita ng wasto ang tunay na kondisyon ng lipunan gamit ang kritikal na salamin ng pagsusuri halimbawa ng Frankfurt School. Ang mga usaping ito ay may mahalagang gampanin sa diskurso ni Demeterio.

Sa aking palagay, kaakibat ng kanyang mga pahayag tungkol sa etikal at ideyolohikal na tungkulin ng pilosopiyang Pilipino ay ang pagpapaalala na magkaugnay ang etikal at ideyolohikal na gampanin na dapat mabatid ng mga namimilosopiya. Batay sa diskurso ni Demeterio, umiikot ang mga tungkuling ito sa isang aspekto o sangay ng pamimilosopiya - at ito ay sa panlipunan o politikal na sangay. Ngunit hindi lamang dapat umiikot sa nasabing sangay ang pamimilosopiyang Pilipino kung ang hangarin ay mas mapapaunlad at mapakinang pa ang kaanyuan ng pilosopiyang Pilipino.

Hahatiin ko ang usapin na ito sa dalawang bahagi. Una, bilang isang mahalagang punto sa diskurso ni Demeterio, susubukan kung magbigay ng kaunting detalye ukol sa kanyang di-hayagang pahayag sa tungkulin ng mga namimilosopiya sa pilosopiyang Filipino. Pangalawa, ang magbigay ng puna sa nasabing punto ng kaniyang diskurso.

Sa kanyang akda na Defining the Appropriate Field for Radical IntraState Peace Studies in Filipino Philosophy ${ }^{21}$ sinabi ni Demeterio na: "Filipino philosophy has the ethical burden of spearheading the inter-disciplinary project of the theory and praxis of critique and counter-critique"22 at ito ay makatutulong na

${ }^{21}$ F.P.A. Demeterio III, “Defining the Appropriate Field for Radical Intra-State Peace Studies in Filipino Philosophy," in Academia, <https://www.academia.edu/7340208/Defining the Appropriate Field for Radical Intra-State Peace Studies in Filipino Philosophy $>, 25$. Hereafter cited as "Defining the Appropriate Field."

${ }^{22}$ Ibid.

(c) 2017 Ben Carlo N. Atim

https://www.kritike.org/journal/issue 21/atim december2017.pdf

ISSN 1908-7330

(c) BY-NC-ND 
lampasan ang patolohikal na kondisyon ng pilosopiyang Pilipino. Inilarawan ni Demeterio ang pilosopiyang Pilipino sa ganitong paraan:

Indeed, Filipino philosophy can be easily pictured as a philosophy that is dispassionate, cold, and devoid of libido; a philosophy that is lulled by some plenitude of innocuous things, such as the lofty tenets of scholasticism and humanism, the endless mazes of language and logical reasoning, and the exoticism of oriental thought. ${ }^{23}$

Sa kanyang pananaw, ganitong uri ng pilosopiyang Pilipino mayroon ang ating bansa. Itong kritikal na pagsasalarawan sa katayuan o kondisyon ng pilosopiyang Pilipino ay may mahalagang ugnayan sa kanyang mga ilang akda sa pangalawang yugto ng kanyang diskurso. Dito sa pangalawang yugtong ito pinagtuunan ng pansin ni Demeterio ang pagbibigay ng konkretong larawan sa katayuan o estado at direksyon ng pilosopiyang Pilipino. Makikita na ang: a) paggamit ng interdisiplinaryong pagsusuri gamit ang magkahalong metodolohiya ng dalawang magkaibang disiplina tulad ng pilosopiya at agham panlipunan, b) ang kanyang pagsasalarawan tungkol sa pilosopiyang Pilipino, at c) pagsulong sa kritikal na pilosopiyang Pilipino bilang isang mapagpalayang (emancipatory) uri ng pilosopiya na hindi dayuhan sa tunay na kondisyon ng lipunan, ay mga palatandaan ng mabigat na tungkuling etikal ng mga gustong mamilosopiya sa pilosopiyang Pilipino.

Ang etikal na tungkulin ng mga namimilosopiya sa pilosopiyang Pilipino ay nakasentro sa pagiging kritikal nito sa pagsusuri sa sosyolohikal, ekonomikal, kultural, at politikal na kalagayan ng isang lipunan. Masasabi din natin na may ideolohikal na layunin ang ganitong uri ng tungkuling etikal at ito ay ang ipakita ang totoong nangyayari sa lipunan sa pamamagitan ng pag-aalis sa kamalayan ng tao ang mga huwad na paniniwala at interes dulot ng mapaniil na mga sistemang panlipunan. Mahalaga sa diskurso ni Demeterio ang ideolohikal na programang isinusulong nito. Ibig sabihin ang pilosopiyang Pilipino ay dapat pilosopiyang nagsusuri sa kondisyon ng lipunan at tinutugunan nito ang kakulangan sa pag-unawa sa kondisyon ng lipunan sa pamamagitan ng pagkilos. Kung papaano ang konkretong pagkilos nangyayari ay sa pamamagitan ng pag-impluwensiya sa kamalayan o pag-iisip ng tao para kumilos. Bagaman maganda ang adhikain ni Demeterio ukol sa mga dapat

${ }^{23}$ Demeterio, "Thought and Socio-Politics: An Account of the Late Twentieth Century Filipino Philosophy," in Academia, <https://www.academia.edu/7340249/Thought_and_SocioPolitics an Account of the Late Twentieth Century Filipino Philosophy $>, 15$. 


\section{DEMETERIO AT PILOSOPIYANG PILIPINO}

gawin ng mga namimilosopiya sa pilosopiyang Pilipino, sa aking palagay hindi sapat ang etikal at ideyolohikal na tungkulin lamang para maisakatuparan ang pagpapa-unlad ng pilosopiyang Pilipino.

Una, kailangan din gawin ng mga namimilosopiya ang maghawan ng konseptuwal na kaligiran ng pilosopiyang Pilipino upang sa ganoon ay magkaroon ng malinaw na direksyon at maplano ng pulido ang mga hakbangin na gagawin para mapaunlad ito. Upang magawa ito, mahalaga ang pagkakaroon ng isang malinaw na pamantayan sa paggamit ng salitang 'pilosopiya' at 'pilosopiyang Pilipino' dahil kung wala, hindi maiiwasang maging sabog ang dakilang gawaing ito. Para mangyari ito, ang pagbibigaylinaw sa kung ano ang gamit at pag-unawa natin sa salitang 'pilosopiyang Pilipino' ay mahalaga. Hindi mahirap mangyari ito dahil ang pilosopiya mismo ay may natatanging kakayanan na bumuo ng matibay nitong pundasyon. Sinasabi nga na ang pamimilosopiya ay isang pagpapanday ng mga konsepto (conceptual engineering) ${ }^{24}$ at sa pananaw naman nila Deleuze at Guattari ay sinabing ang pilosopiya ay taga-gawa ng konsepto. ${ }^{25}$

Pangalawa, hindi lamang nakasalalay sa etikal at ideyolohikal na tungkulin ng mga namimilosopiya ang kapalaran ng pilosopiyang Pilipino kundi pati na din sa kakayanang intelektuwal ng mga namimilosopiya na ipamalas ang angking galing upang sa ganun ay maramdaman ng tao ang kahalagahan nito sa kanilang buhay. Sa ganitong paraan ay makakakuha tayo ng malasakit sa kanila na maaaring tulay para mapansin ng pamahalaan ang kahalagahan ng pilosopiya sa bansa. Mahalaga ang tungkuling ginagampanan ng gobyerno para sa pagpapayabong ng pilosopiya at ng pilosopiyang Pilipino.

Pangatlo, ang mga namimilosopiya sa pilosopiyang Pilipino ay dapat masipag manaliksik upang makapagpalimbag ng mga akda tungkol sa pilosopikal na Pilipinong pananaw sa mga problemang may pangkalahatang (universal) interes. Dagdag pa rito ay ang pagsali sa mga makabuluhang pilosopikal na diskusyon o debate ng mga kilalang pilosoper ng bansa. Sa ating akademikong buhay bilang mga namimilosopiya, madalang tayo nakatatagpo ng mga nagtutunggaling o nagsasagutang mga pilosoper gamit ang sulat sa ilang pilosopikal na isyu. Marahil hindi pa tumalab sa kulturang akademiko ng bansa ang ganitong makabuluhang gawain.

Bilang paglilinaw, hindi naman sinasabi ni Demeterio na itong uri ng tungkuling etikal lamang ang makapag-papaunlad sa pilosopiyang Pilipino. Ang konteksto ng kanyang pagtingin sa pilosopiyang Pilipino at sa patolohikal na kondisyon nito ay maaaring magamot kung ang pilosopiyang Pilipino ay aktibong makisangkot sa usaping panlipunan kaysa maglaan ng

${ }^{24}$ Simon Blackburn, Think: A Compelling Introduction to Philosophy (Oxford: University Press, 1999), 3.

${ }^{25}$ Deleuze and Guattari, What is Philosophy?, 7.

(c) 2017 Ben Carlo N. Atim

https://www.kritike.org/journal/issue 21/atim december2017.pdf

ISSN 1908-7330

(cc) BY-NC-ND 
panahon sa mga pilosopikal na gawaing walang praktikal na pakinabang. Sa madaling sabi, maliban sa ideyolohiyakal at pagsesentro ng tungkulin etikal sa pilosopiyang panlipunan at politika sa bansa, maaari din tingnan ang iba pang bagay na makatutulong sa mga namimilosopiya. Ibig sabihin, maaari ding sakupin ng tungkuling etikal ng mga namimilosopiya ang pagsusuring pilosopikal sa ilang suliranin sa ibang sangay nito. Halimbawa, maari tingnan ang ilang sangay ng pilosopiya tulad ng epistemolohiya, lohika, estetika, metapisika, relihiyon, at wika sa pagsusuri ng pilosopiyang Pilipino. ${ }^{26}$

Kung ang pilosopiyang kritikal ng Frankfurt ay may malakas na potensyal sa pagpapaunlad ng pilosopiyang Pilipino ayon kay Demeterio, may iilang pilosopikal na diskurso naman na dapat nang lisanin pati ang mga pamamaraan nito.

\section{Paglisan sa lilang Pilosopikal na Diskurso at Ang mga Pamamaraan Nito}

Anong pilosopiya ang dapat nang lisanin at ano naman ang dapat pang pagtuunan ng pansin, lakas, at oras ayon kay F.P.A. Demeterio?

Ang kontemporaryong panahon ay maihahalintulad sa isang bahaygagamba o di kaya ay yaring-lambat kung saan walang masasabing pinakasentro, pundasyon o saligan ang batayan ng lahat ng ginagawa ng tao. Sa isang desentralisadong lipunan, ang hamon sa pilosopiya ay ito: Papaano nito maibabahagi ang sarili upang maging kapaki-pakinabang? Sinabi ni Stephen Hawking sa kanyang akda na The Grand Design na ang pilosopiya sa kabuuan ay isa ng patay. ${ }^{27}$ Marahil nakita ni Hawking na walang pag-unlad na nangyayari sa pilosopiya hindi katulad ng sa likas na agham. Sa madaling sabi, ang pilosopiya ay isa ng passé o bakya (out of fashion). Ngunit, ano nga ba ang tinutukoy ni Hawking sa pagsabi na wala ng silbi ang pilosopiya? Ano man ang tinutukoy ni Hawking dito ay hindi na kailangan palawakin pa dito. Ang mahalaga ay ang malaman ang kahalagahan ng kanyang deklarasyon laban sa pilosopiya sa kontemporaryong panahon. Una sa lahat ang deklarasyon ni Hawking ay isa ding passé. Bago pa man niya napagtanto ito, nakita at naramdaman na ng ilang pilosopo tulad nila Heidegger, Carnap, Rorty, at Wittgenstein ang nalalapit na pagtatapos ng pilosopiya. ${ }^{28}$ May ilang kontemporaryong pilosopo din ang tumingin sa katayuan ng pilosopiya sa

\footnotetext{
${ }^{26}$ Bagaman ito ay makikita sa mga talang ipinakita ni Demeterio sa mga ilang mga akda, ito ay hindi hayagan dahil batay sa tala, gumamit si Demeterio ng ibang marka ng pilosopiya at hindi marka na tumutukoy sa sangay ng pilosopiya.

27 Stephen Hawking and Leonard Mlodinow, The Grand Design (London: Bantam Books, 2011), 1.

${ }^{28}$ Ang dahilan ni Hawking sa kanyang sinabi ay hindi maituturing pilosopikal. 
makabagong panahon. Isa na dito ay si Alain Badiou. Sa kanyang akda na Infinite Thought, sinasabi niya na may tatlong orientasyon ang pilosopiya sa kontemporaryong panahon. Ito ay hermenyutika (Heidegger at Gadamer), analitikal (Wittgenstein at Carnap), at postmodernismo (Lyotard at Lacan). ${ }^{29}$ Sa tatlong magkakaibang orientasyon na ito, sabi ni Badiou, magkakaiba man ang mga pinanggagalingan at pananaw sa iba't ibang pilosopikal na paksa ay mayroong naman silang pinagkakasunduang dalawang mahahalagang bagay, at ito ay: a) negatibong pananaw sa kalagayan ng pilosopiya tulad ng pananaw sa metapisika at katotohanan. Sinasabi ni Badiou na nagkakaisa ang tatlong orientasyon sa paniniwala sa katapusan ng metapisika at ng klasikal na ideya ng katotohanan; b) sa positibong pananaw naman, nagkakaisa ang tatlo sa paniniwala tungkol sa kahalagahan ng wika (language). Halimbawa, ang hermeneyutika ay binubuo ng interpretasyon ng speech acts, ang analitikal naman ay tungkol sa mga utterances at rules ng wika sa pagbubuo ng kahulugan; at c) panghuli, ang postmodernismong orientasyon ay pinapalaganap ang ideya ng iba't-ibang klase o pluralismo o fragments, at mga uri ng diskurso sa pagkawala ng pagkakaisang-uri (homogeneity). ${ }^{30}$ Makikita sa negatibong pananaw sa pilosopiya ng tatlong orientasyon ang problema ng pilosopiya pagdating sa gamit at papel nito bilang isang akademikong disiplina. ${ }^{31}$ Ayong kay Badiou ang tradisyonal na pilosopiyang nakasentro sa metapisika at katotohanan ay ang dahilan ng unti-unting paghina o pagwala bilang isang disiplina.

Ito din marahil ang tinutukoy ni Demeterio sa kanyang puna na para umusad at umunlad ang pilosopiyang Pilipino kailangan ng lisanin ang ilang mga pilosopikal na tradisyon na wala naman naidudulot na maganda. Ayon sa kaniya: "In their ${ }^{32}$ dramatic novelty and exotic foreigness, it became very easy for the Filipino philosophy professor to be lost in their profundity, forgetting in the process that philosophy is ought to be a theoretical engagement with reality. ${ }^{33}$ Tinukoy ni Demeterio ang uri ng mga tradisyon ng pilosopiya na kanyang tinawag na "dispassionate, cold, and devoid of libido; a philosophy that is lulled by some plenitude of innocuous things, such as the lofty tenets of scholaticism and humanism, the endless mazes of language and logical reasoning, and the exoticism of oriental thought." 34 Mapapansin rito ang tatlong magkakaibang tradisyon o diskurso na maituturing may mababang

\footnotetext{
${ }^{29}$ Alain Badiou, Infinite Thought: Truth and the Return to Philosophy, trans. and ed. by Oliver Feltham and Justin Clemens (London: Continuum, 2004), 43-44.

${ }^{30} \mathrm{Ibid} ., 46$.

${ }^{31}$ Sa katunayan sinabi ni Heidegger na ang pilosopiya ay natapos kay Nietzsche.

32 Tinutukoy dito ni Demeterio ang tradisyong pilosopikal ng Ateneo de Manila (existential/continental philosophy) at Unibersidad ng Pilipinas (logical positivism/linguistic philosophy).

${ }^{33}$ Demeterio, "Thought and Socio-Politics," 18. Italics mine.

${ }^{34}$ Ibid., 5. Italics mine.

(c) 2017 Ben Carlo N. Atim

https://www.kritike.org/journal/issue 21/atim december2017.pdf

ISSN 1908-7330
}

(c) BY-NC-ND 
halaga sa gawain ng pilosopiyang Pilipino. Ito ay ang scholasticism, logical positivism/analytic philosophy, at oriental philosophy. Sa puntong ito, mababatid na natin kung alin sa mga pilosopikal na diskurso o gawain ang dapat lisanin dahil wala itong konkretong maitutulong sa paglago ng pilosopiyang Filipino. Ito ay pinatunayan ni Demeterio sa kanyang akda na makikita sa pangalawang yugto ng kanyang diskurso.

Pinatunayan ni Demeterio na ang mga nabanggit na tradisyon sa itaas ay may mababang potensyal sa pagpapaunlad ng pilosopiyang Pilipino. Ayon sa kanya, ang mga ito ay ang mga sumusunod: a) Skolastiko/Tomistikong pilosopiya, b) Pag-aaral ng mga banyagang sistemang pilosopikal, at c) Tekstuwal na paglalahad ng banyagang sistemang pilosopikal. ${ }^{35}$ Ang huling dalawang (b \& c) diskurso napapaloob ang logical positivism/analytic at oriental philosophy. Malinaw sa nabanggit na ang diskursong Tomistiko ay ang pangunahing diskurso na may mababang potensyal sa pagpapaunlad ng pilosopiyang Filipino. Sa katunayan, sangayon si Demeterio sa pananaw ni Quito na ang Tomistikong pilosopiya ay isang hadlang sa pagpapalago ng pilosopiya sa bansa lalo't higit ng pilosopiyang Filipino: "Thomism is a great stumbling block for Filipino philosophy." 36

Sa isang akda naman, batay sa mga nakalap niyang datos, pinakita ni Demeterio na mayroong labing-dalawang diskurso sa pilosopiyang Pilipino. ${ }^{37}$ Ang kanyang layunin ay maipakita, gamit ang talaan na mayroong limang diskursong may mataas na potensyal na mapapaunlad nito ang pilosopiyang Pilipino. Ito ay ang mga sumusunod: a) Filipino Philosophy as the Appropriation of Foreign Theories, b) Filipino Philosophy as Academic Critical Analysis, c) Filipino Philosophy as Research on Filipino Ethics and Values, d) Filipino Philosophy as the Appropriation of Filipino Spirit, at e) Filipino Philosophy as the Study on the Presuppositions and Implications of the Filipino Worldview. ${ }^{38}$ Kung titingnan ng maigi ang limang diskursong nabanggit, makikita na tatlo lamang rito ang maituturing na pilosopikal (sa istriktong gamit ng salita). Ito ay ang $a, b$, at $e$. At ang mga ito ay maaring may kinalaman o walangkinalaman sa scholasticism, logical positivism/analytic, at oriental philosophy. Sa kabuuan, pinapalagay ni Demeterio na mayroong ilang diskursong pilosopikal na walang pakinabang sa pag-unlad ng pilosopiyang Pilipino. At

${ }^{35}$ Demeterio, "Status of and Directions for 'Filipino Philosophy,', 22-23.

${ }^{36}$ Demeterio, "Re-Reading Emerita Quito," 6.

${ }^{37}$ Ang mga nasabing datos ay nakuha ayon sa kanya sa pamamagitan ng paggamit ng google scholar, interbyu off-line-online, at sa ilang babasahin sa pilosopiyang Pilipino.

38 F.P.A. Demeterio III, "Assessing the Development Potentials of some Twelve Discourses of Filipino Philosophy (Abstract and Introduction of a Paper Published in Philippiniana Sacra," in Academia, https://www.academia.edu/12035138/Assessing the_Developmental_Potentials_of_Some_Twelve_Discourses_of_Filipino_Philosophy_Abstract and Introduction of a Paper Published in Philippiniana Sacra $>$.

(C) 2017 Ben Carlo N. Atim

https://www.kritike.org/journal/issue 21/atim december2017.pdf

ISSN 1908-7330

(cc) BY-NC-ND 
kung bakit walang pakinabang ang mga ito ay dahil hindi nakatutulong sa pag-unawa at pagsusuring kritikal ng lipunan.

Ngunit kung susuriin natin ng maigi, hindi matibay ang batayan ng puna ni Demeterio. Una, hindi nasusukat ang kabuluhan o di-kabuluhan ng isang tradisyon sa dami o kaunti na gumagawa nito. Pangalawa, bawat pilosopikal na tradisyon ay may kanya-kanyang kahinaan. Pangatlo, hindi maaaring ikahon sa kanyang historikal na panahon ang tradisyon para masabing wala ng halaga ito sa ngayon kung ito ay panahon pa ni Aquinas. Ang pang-apat ay konteksto. Kung ilalagay sa tamang konteksto ang bawat tradisyon makikita na ito ay may kanyang angking kabuluhan. Halimbawa, sa usaping pilosopiya ng relihiyon maaaring gamitin ang Tomistikong pananaw sa pagsusuri ng karanasang relihiyoso ng mga Pilipino, o dili kaya ang ordinary-language philosophy ni J.L. Austin o Paul Grice o John Searle sa pagsusuri ng mga pananalita ng mga kabataan Pilipino ngayon. Samakatuwid, pinapalagay ni Demeterio na mayroong mga diskursong pilosopikal na kailangang lisanin pati ang mga pamamaraan nito.

\section{Ang Uri ng Pilosopiyang Pilipino ni Feorillo Petronilo Demeterio: Kritikal na Pilosopiyang Pilipino}

Sa unang tingin payak ang konsepto ng Kritikal na Pilosopiyang Pilipino (KPP) ni Demeterio. Sa katunayan, walang wastong pagkakahulugan na makikita sa kanyang diskurso tungkol dito. Gayunpaman, mauunawaan natin ito sa pamamagitan ng kanyang paniniwala na ang pilosopiyang Pilipino ay dapat nakasentro sa kritikal na pagsusuri sa kalagayan o kondisyon ng lipunan. Ang pilosopiyang 'kritikal' ay mayaman sa pananaw at tradisyon. Katunayan, maririnig sa kabuuang diskurso ni Demeterio ang boses ng mga kritikal na pilosopo ng Frankfurt School tulad ni Habermas.

Sa kanyang sanaysay na Defining the Appropriate Field for Radical IntraState Peace Studies in Filipino Philosophy, sinabi ni Demeterio na mayroong apat na malinaw na tradisyon ang pilosopiyang Pilipino at ito ay ang mga sumusunod: "1) scholasticism, 2) the influx of western philosophical theories, 3) Filipino philosophy as interpretation of Filipino identity and world-view, and 4) Flipino philosophy as critique of the Philippine social and economic structures." ${ }^{39}$ Ngunit sa apat na tradisyong ito ang pang-apat (4) na tradisyon ang sinasabi ni Demeterio na makapagbibigay ng nararapat at matibay na tradisyon sa pilosopiyang Pilipino. Ito ay dahil sa:

${ }^{39}$ Demeterio, “Defining the Appropriate Field", 9.

(c) 2017 Ben Carlo N. Atim

https://www.kritike.org/journal/issue 21/atim december2017.pdf

ISSN 1908-7330

(cc) BY-NC-ND 
Scholasticism could not provide an appropriate tradition because scholasticism in first place emerged prior to the Durkheimian discovery of society and the Marxist formulation of structural analysis. The influx of western philosophical theories could also not provide an appropriate tradition, because it is not even a single tradition in itself but a collection of some purposeless expounding of one foreign philosophy after another ... Lastly, Filipino philosophy as interpretation of Filipino identity and world-view could also not provide an appropriate tradition becase of its descriptive ethnographic concerns which is different from the diagnostic and prescriptive concerns of radical peace studies. ${ }^{40}$

Sa konteksyon ng usapin ni Demeterio ukol sa araling kapayapaan (peace studies), sinasabi niya na ang kritikal na pilosopiyang Pilipino ay may sapat na tradisyon at karapat-dapat na magbigay ng masusi at kritikal na pagpupuna sa sosyolohikal, politikal, at ekonomikal na estado ng lipunan ng bansa. Subalit, hindi man binigyan ni Demeterio ng malinaw na kahulugan ang kanyang paggamit sa salitang Kritikal na pilosopiyang Pilipino sa nasabing akda, makikita naman ito sa ilan niyang akda na nagpapaliwanag sa kung ano ang tinutukoy ng kanyang sinasabing 'kritikal' na pilosopiyang Pilipino.

Sa sanaysay na Thought and Socio-Politics ni Demeterio, ipinaliwanag niya ang kanyang pananaw tungkol sa KPP. Napapaloob dito ang ilang mga pahayag at puna tungkol sa katayuan at kalagayan ng pilosopiyang Pilipino. ${ }^{41}$ Sinasabi ni Demeterio na ang KPP ay may matatag na tradisyon dahil ito ay nagsimula pa noong panahon ng kilusang Propaganda sa panahon ng pananakop ng mga Kastila sa Pilipinas at lalong umusbong pagsapit ng panahon kung kailan namayagpag ang Critical Theory sa Europa. ${ }^{42}$ Ngunit naputol ito noong panahon ng Batas Militar sa bansa. Dahil ayon kay Demeterio, bago pa ang pagdeklara ng Batas Militar ni Marcos noong Septyembre 21, 1972 na humantong sa hindi kanais-nais na mga kaganapan hanggang matapos ito noong Enero 17, 1981, malakas ang puwersa ng kritikal na pamimilosopiya sa bansa. Ngunit ito ay pansamantalang humina at bumalik ang sigla nito pagkatapos ng rehimeng Marcos. Dagdag pa niya, sa apat na tradisyong nabanggit, ang kritikal na pilosopiyang Pilipino ang may kongkretong programa sa pagsusuring

\footnotetext{
${ }^{40} \mathrm{Ibid}$. Italics is mine.

${ }^{41}$ Sa katunayan, maaaring sabihing ang akdang ito ay pangunahing tanda at reperensya sa kanyang diskurso tungkol sa KPP.

${ }^{42}$ Demeterio, "Thought and Socio-Politics," 3. Ito ay maituturing pangunahing reperensya ng kanyang pananaw sa konsept ng 'Kritikal na Pilosopiyang Filipino'.
} 
panlipunan: "critical philosophy comes with a definite agendum which is to critique the Philippine cultural, social, economic and political structures." 43 Ito rin ay may pambansa at teoretikal na layunin-ang gamutin ang patolohikal na estado ng bansa at ng pilosopiyang Pilipino. Dagdag pa ni Demeterio: "the urgency of a critical Filipino philosophy to finally emerge from its pathological state is not a mere academic desire of some armchair intellectuals, but is something that is actually premised on a social, cultural and national interest." 44

Tinuturing din ni Demeterio ang kritikal na pilosopiyang Pilipino bilang isang diskursong mas makabuluhan kumpara sa ibang uri ng pamimilosopiya sa bansa. Ito ay dahil ang kritikal na pilosopiyang Pilipino ay may praktikal na tingin at gamit sa mga pangyayari sa paligid, tumutulong na pakilusin ang mga tao sa tulong ng ideolohikal nitong estraktura, at higit sa lahat may direktang epekto sa pamumuhay ng tao. Bukod pa sa nabanggit, ang pilosopiyang kritikal ay umaangkop sa panahon na kinalalagyan nito at sumasabay sa agos ng postmodernismong kondisyon ng lipunan. Kaya naman ganoon na lamang ang pagkahumaling ni Demeterio sa pilosopiyang kritikal sapagkat maliban sa nabanggit na mga dahilan, ayon sa kanya, ito rin ay magsisilbing tagapagligtas ng pilosopiyang Pilipino: "The salvation for Filipino philosophy may come from retrieving and reliving the forgotten movement of the early indigenous phase of critical Filipino philosophy." 45 Samakatuwid, ang gamit ng pilosopiyang kritikal ni Demeterio ay sumasaklaw lamang sa politikal na karakter nito. Hindi saklaw ng pilosopiyang kritikal ni Demeterio ang ibang aspekto tulad ng epistemolohiya, estetika, at etika. Gayunpaman, sinasaklaw pa din ng konsepto ng pilosopiyang kritikal ni Demeterio ang mga pangunahing tesis ng teoryang kritikal. Ayon kay Raymond Geuss mayroong tatlong esensyal na anyo ang teoryang kritikal at ito ay ang sumusunod: a) bilang gabay para sa pagkilos (human action), b) bilang anyo ng kaalaman (knowledge), at c) bilang isang reflective na gawain. ${ }^{46}$

Sa kabuuan, tinuturing ni Demeterio na mahalaga ang ginagampanang tungkulin ng pilosopiyang kritikal sa diskurso ng pilosopiyang Pilipino. Ito ay isang pilosopikal na metodo sa pagsusuri ng tunay na kalagayan ng lipunan kung saan ang tao ay umiiral. Dito din maaring maiuugnay ang pananaw ni Roland Theuas Pada sa kanyang artikulo na The Methodological Problems of Filipino Philosophy at ni Emmanuel De Leon. Sinusundan at sinusuportahan ni Pada at De Leon ang pananaw ni

\footnotetext{
${ }^{43}$ Ibid., 17.

${ }^{44}$ Ibid., 18.

${ }^{45}$ Ibid., 23.

${ }^{46}$ Geuss, The Idea of Critical Theory, 2.
}

(c) 2017 Ben Carlo N. Atim

https://www.kritike.org/journal/issue 21/atim december2017.pdf

ISSN 1908-7330

(c) BY-NC-ND 
Demeterio pagdating sa pamimilosopiya sa pilosopiyang Pilipino. ${ }^{47}$ Pangunahing layunin ng pilosopiyang kritikal na isinusulong ni Demeterio ay ang makisangkot sa pagsusuri sa kondisyon ng lipunan at bumuo ng kritikal na mga puna tungkol dito. Layunin din ng pilosopiyang kritikal ang gabayan ang bawat tao na nabibilang sa isang lipunang kontrolado ng iilan na mag-isip at alamin ang mga totoo nitong interes upang sa ganun ay maiwasan ang mapanlinlang na sistema nito. At panghuli, ang pilosopiyang kritikal ay nagbibigay pag-unawa sa kung ano ang ibig sabihin ng lipunan. Sa diskurso ni Demeterio, nakasentro ang pilosopiyang kritikal sa pagmamasid at pagsusuri sa politikal, sosyolohikal, at ekonomikal na suliranin ng lipunan. Sa ganitong paraan, ayon sa kanya, mas napapaunlad natin ang pilosopiyang Pilipino.

\section{Konklusyon}

May dalawang pangunahing layunin ang papel na ito. Una, ang magbigay ng mahahalagang puntos sa diskurso ni F.P.A. Demeterio tungkol sa pilosopiyang Pilipino at ito ay ang sumusunod: a) ang pagbibigay ng malinaw na pahayag tungkol sa estado at direksyon ng pilosopiyang Pilipino, b) ang kahalagahan ng interdisiplinaryong metodo sa pananaliksik sa pilosopiyang Pilipino, c) ang mga dapat gawin ng namimilosopiya, at d) ang paglisan sa ilang pilosopikal na gawain at pamamaraan nito. Ang pangalawang layunin ay ang pagbigay pansin sa konsepto, kahalagahan, at gamit ng kritikal na pilosopiyang Pilipino. Bagaman ipinakita din ng papel na ito ang kahinaan at kakulangan ng matibay na argumento ang mga puntos ng diskurso ni Demeterio, hindi ito nangangahulugan ng paglisan sa kanyang mga panukala. Bagkus ito ay isang panawagan sa mga nagsusumikap na maunawaan pa lalo at mapalago ang pilosopiyang Pilipino na maglaan at gumugol pa ng maraming panahon para sa malalimang pagsusuri at paghahanap ng matitibay na sagot o solusyon sa panloob na suliranin ng Pilosopiyang Filipino.

Philosophy Department, Saint Paul Seminary, Silang Cavite, Philippines

${ }^{47}$ Roland Theuas DS. Pada, "The Methodological Problems of Filipino Philosophy," in Kritike: An Online Journal of Philosophy 8:1 (2014), 24-44. See also Emmanuel C. De Leon, “Ang Pilosopiya at Pamimilosopiya ni Roque J. Ferriols, S.J." 


\section{DEMETERIO AT PILOSOPIYANG PILIPINO}

\section{References}

Badiou, Alain, Infinite Thought: Truth and the Return to Philosophy, trans. and ed. by Oliver Feltham and Justin Clemens (London: Continuum, 2004).

Blackburn, Simon, Think: A Compelling Introduction to Philosophy (Oxford: University Press, 1999).

De Leon, Emmanuel C., "Ang Pilosopiya at Pamimilosopiya ni Roque J. Ferriols, S.J.: Tungo sa Isang Kritikal na Pamimilosopiyang Filipino," in Kritike: An Online Journal of Philosophy 9:2 (2015).

, "Emerita S. Quito (1929--): Ang Ugat ng Isang Panibagong Direksiyon ng Pamimilosopiya sa Pilipinas," in Malay 29.2 (2017).

Deleuze, Gilles and Felix Guattari, What is Philosophy?, trans. by Hugh Tomlinson and Graham Burchell (New York: Columbia University Press, 1991).

Demeterio, F.P.A. III, “Assessing the Development Potentials of some Twelve Discourses of Filipino Philosophy (Abstract and Introduction of a Paper Published in Philippiniana Sacra," in Academia, https://www.academia.edu/12035138/Assessing the Developmenta 1 Potentials of Some Twelve Discourses of Filipino Philosophy Abstract and Introduction of a Paper Published in Philippinian a Sacra $>$.

"Defining the Appropriate Field for Radical Intra-State Peace Studies in Filipino Philosophy," in Academia, $<$ https://www.academia.edu/7340208/Defining the Appropriate Fi eld for Radical Intra-State Peace Studies in Filipino Philosophy>.

"Re-Reading Emerita Quito's Thoughts Concerning the Underdevelopment of Filipino Philosophy," in Academia, $<$ https://www.academia.edu/7340197/Re-Reading Emerita Quitos Thoughts Concerning the Underdevelopment of Filipino Philosophy>.

"Speculations on the Dis/Junction Point between Philosophy and the Social Sciences," in Academia $<$ https://www.academia.edu/7340224/Speculations on the Dis Jun ction Point between Philosophy and the Social Sciences $>$. "Status of and Directions for 'Filipino Philosophy' in Zialcita, Timbreza, Quito, Abulad, Mabaquiao, Gripaldo and Co," in

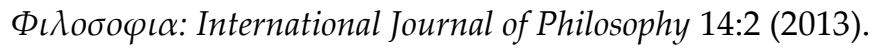

"Thought and Socio-Politics: An Account of the Late Twentieth Century Filipino Philosophy," in Academia, <https://www.academia.edu/7340249/Thought and Socio- 
Politics an Account of the Late Twentieth Century Filipino Phil osophy>.

Descartes, Rene, Meditations on First Philosophy, trans. by John Cottingham (Cambridge: Cambridge University Press, 1996).

Geuss, Raymond, The Idea of Critical Theory: Habermas and the Frankfurt School (London: Cambridge, 1981).

Hawking, Stephen and Leonard Mlodinow, The Grand Design (London: Bantam Books, 2011).

Liwanag, Leslie Anne L., “Ang Pilosopiya ni Emerita S. Quito," Kritike: An Online Journal of Philosophy 10:1 (2016).

"Ang Pilosopiya ni Sr. May John Mananzan, OSB," in Kritike: An Online Journal of Philosophy, 9:2 (2015).

Mabaquiao, Napoleon, "Isang Paglilinaw sa Kahulugan at Kairalan ng Pilosopiyang Filipino," in Malay 24:2 (2012).

Pada, Roland Theuas DS., "The Methodological Problems of Filipino Philosophy," in Kritike: An Online Journal of Philosophy 8:1 (2014). 